\title{
Issues in Lightweight Encryption Algorithm for mHealth
}

\author{
Tasnuva Ali, A. H Azni, Nur Hafiza Zakaria
}

\begin{abstract}
The mHealth is the eventual future of the subsequent time of portable nicely being that may regulate the winning worldview of hobby and permit to decorate access of affected person's' data with specialists and human offerings ventures. The records safety of all layers of $m$ Health layout is taken into consideration as colossally noteworthy in view of searching after patients' facts over remote medium. The essential issues of mHealth are the overall engineering, protection and safety problems with information execution, accessibility and dependability of the devices. in this way, it's miles key to have a easy protection tool in $\mathrm{mHealth}$ format to decide each this type of confinements. furthermore, the cryptography can also additionally moreover prompt restriction the degree of misfortune carried out on sufferers' records from unapproved customers but their usage in mHealth is as yet contested. finally, this paper examines the problems in lightweight encryption calculations to make a near studies amongst them with recognize to records safety in a long way off reputation layer. From the audit, the proposed calculation of 3-D RECTANGLE may offer higher determine protection for its pivot contrasted with distinct lightweight calculations. This near audit likewise finally finally ends up with some exploration bearings in mHealth cryptography for planning validated $m$ Health arrange in future.
\end{abstract}

Record phrases: mHealth, mild-weight set of guidelines assault,Safety.

\section{INTRODUCTION}

Telehealth or also known as cell health (mHealth) is the conveyance of a long way flung social coverage administrations like well being counsels or evaluations through the posted communications framework. This new innovation conveys more and more information centered social coverage management to enhance the general productivity of medicinal services frameworks making use of PDAs which might be taken into consideration as captivating ranges for human services rehearses due to its few highlights like clean to recognize interface, inescapability, computational capacities, accessibility, labored in-sensors, community and portability [1]. except, the amount paces of facts association over cellular structures are handy in severa nations which make the movement from artwork place ranges to flexible with far flung arrangements. moreover, mHealth can conceivably reduce the fee of furnishing medicinal offerings with the increasing requests of the maturing population in lowering component economic subjects [2]. hence, mHealth assumes a great approach inside the public

Revised Version Manuscript Received on August 19, 2019.

Tasnuva Ali, Daffodil International University, Dhaka, Bangladesh.

Dr. A. H Azni, Universiti Sains Islam Malaysia (USIM), Bandar Baru Nilai Malaysia.

Nur Hafiza Zakaria, Universiti Sains Islam Malaysia (USIM), Bandar Baru Nilai, Malaysia. area, as an instance, it offers remote and rustic patients' the front of restorative interest, improves have an effect on of restrained physician assets, lessens rate of interest conveyance with health center re-confirmation and builds up experts' productiveness with giving easy get right of entry to to new authority. however the reality that its

options, severa associations were built up the improved mHealth framework, but their protection willpower isn't always plenty effective to defend information from each unmarried viable attack. therefore all the beyond explores right here have commonly targeted around exactness and assaults on affected man or woman's records.

The affiliation of the paper is as regular with the subsequent: phase II examines the issues in protection requirements, at that problem this paper talks approximately problems recognized with safety assaults and encryption strategies in phase III and segment IV in my opinion. subsequent, the correlation research and proposed association from the three associated troubles is proposed in segment $\mathrm{V}$ and pursued by way of way of an end in phase VI.

\section{ISSUES IN PROTECTION NECESSITIES FOR MHEALTH}

\section{A. wi-fi notion Layer}

The mHealth are cloud framework dependent on IoT include of 5 layers which is probably popularity layer, put together layer, middleware layer utility layer and employer layer as appeared in Fig.1.

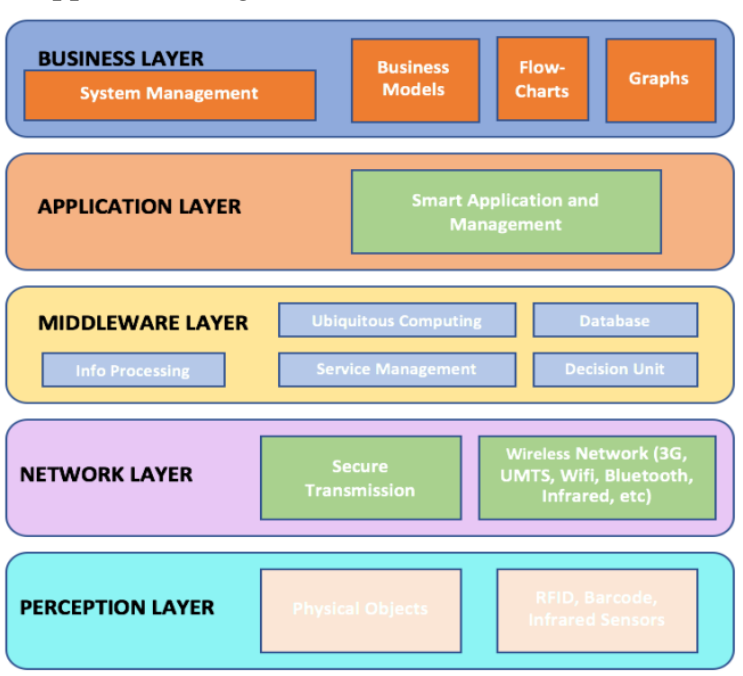

Fig. 1. General IoT Architecture

Published By:

Blue Eyes Intelligence Engineering 
The wi-fi belief layer is otherwise called 'device Layer' assume significate process to see the facts from mHealth situation. [6]. It incorporates of the bodily articles and sensor gadgets, for instance, RFID labels, standardized identity name, GPS or digital digicam for

records gathering. this accretion basically manages the distinguishing evidence and accumulation of articles precise information with the useful resource of the sensor gadgets. Sensor hubs cozy, transmit and system the statistics of the bodily international to carry out attending to the facts of factors. the general public of these sensor hubs are despatched in unmanned circumstance, and due to missing a achievement coverage measures, the signal presented to the open are powerless against malevolent assaults.

B. protection Requirement in belief Layer

MHealth transmits sensitive statistics over in the a ways off medium which desires to assure sufferers' safety in opposition to each single vindictive movement. Fig. 2 portrays the vital requirements of securing patients' information in discernment layer for mHealth.

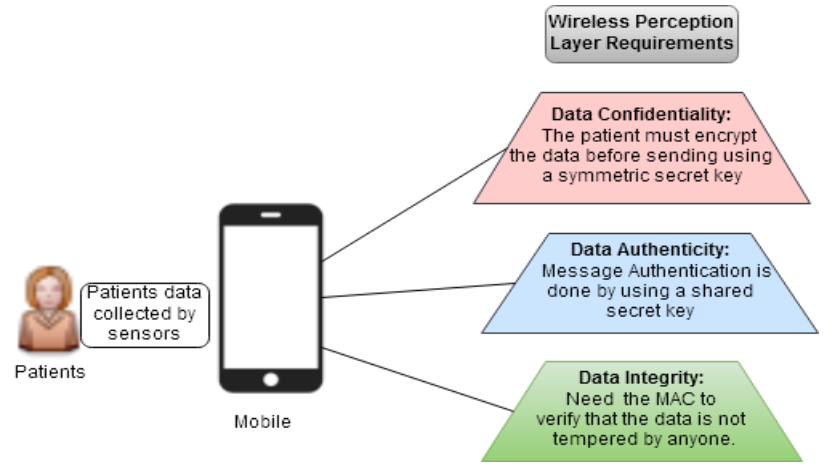

Fig. 2. Security Requirements for Perception Layer

The facts respectability, validness and type are the critical concentrating factor to give safety on patients' facts in an extended manner off discernment medium. As safety is needed in those 3 portions because it have to be, for that reason numerous works had been proposed to characteristic sufferers' safety on records earlier than transmitting to cloud or one-of-a-kind tool layers. between them, the primary artwork proposed with the useful resource of $\mathrm{X}$. Lin to reputation on protection aware information transmission in competition to global listening in eHealth framework on the identical time as ignoring confirmation and statistics uprightness troubles [6]. moreover, L. Guo and C. Zhang center spherical confirmation techniques with numerous cooperations amongst severa appealing substances in mHealth frameworks [7]. in addition, concentrating facts trustworthiness, Weerasihnhe and Rajarajan advise a safety discipline for token manage framework to assist blanketed outdoor correspondence with social coverage suppliers, put together administrators and other associated correspondence events [8]. along those strains, distinct works have been proposed with reference to records honesty and credibility to guarantee installation correspondence amongst specialists' and patients' without presenting recognition layer safety in mHealth. additionally, the ones overviews just gave the shape or research headings in place of explicit protection solutions for make certain mHealth information in a long way flung popularity layer.

In this way, mHealth frameworks are experiencing real safety troubles that have an impact on all substances of framework, for instance, affected character and doctor with differing levels. The exceptional protection problems are: community and portability of mobile phones, terrible shape of mHealth frameworks, feeble utilization of passwords, clean content material material stockpiling and transmission of statistics, absence of pointers

furthermore, foundations for mHealth frameworks safety and shortage of supervision on mHealth applications. alongside the ones strains, the a success advances must be taken within the course of conquering the present day-day protection troubles in mHealth records transmission to ensure sufferers' safety in future.

\section{PROBLEMS IN SECURITY ASSAULTS IN MHEALTH}

The mHealth has an amazing drawing close to boom the man or woman of human services ventures however furthermore rises real safety and safety traumatic conditions as referenced before. The affected man or woman's data is transmitting in discernment layer in desire to using laptop or pc for facts accumulation that is portrayed in Fig. three. This remark layer likewise wishes enough protection which might be practicable with the useful resource of encoding mHealth statistics making use of encryption strategies to guard from unapproved clients. in any case, the precept problem is to choose out an excellent encryption calculation for this sediment as they may be confronting such large numbers of attacks like differential attacks, at once attacks, associated key assaults, slide assaults and so on which want to restriction for structuring valid mHealth calculation later on.

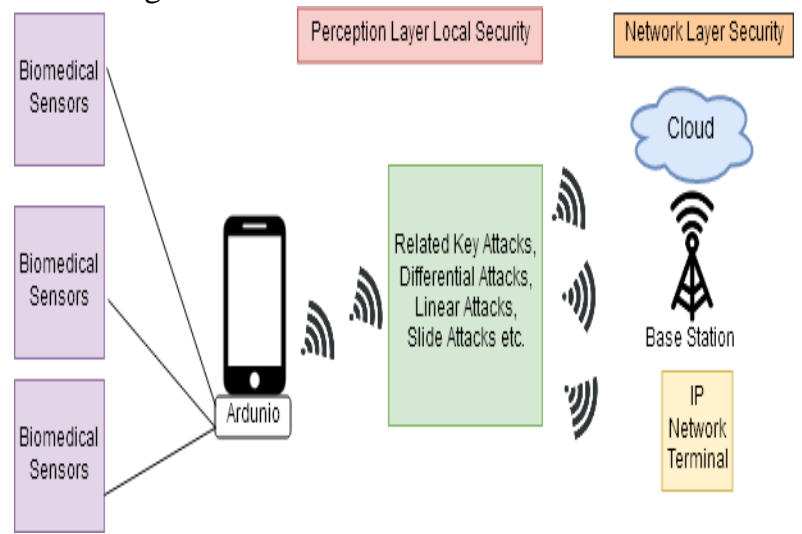

Fig. 3. Types of Attacks in Perception Layer

Rajindra and Kotz deliver a rundown of open safety problems with numerous safety issues in mHealth software and incorporated versatile telemedicine framework with certain tips [9-10]. additionally, Knudsen [11] and Biham [12] freely displayed a cryptanalytic approach using associated keys, referred to as the associated-key assault which applies differential cryptanalysis to the determine with associated one-of-a-kind obscure keys. a few other assault this is cloth to an substantial affiliation of rectangular figures is referred to as Differential assault displayed via

Biham [12] at the same time as Knudsen supplied 
truncated differentials attacks which have become linked to lower rounds square figures [13]. some one of a kind model of differential cryptanalysis with hazard zero is an terrific differential which has later been effectively related variously to nearly damage the parent Skipjack [14]. therefore D. Wagner provided the boomerang attack, which lets in interfacing differentials elements of a determine key that don't cover in the middle anyways, became healthy to break the determine COCONUT ninety eight [15]. in the long run, M. Roughages gives an academic workout on Linear assault which attempts to take the growth of excessive probability without delay articulations concerning plaintext bits, figure content bits and subkey bits [16].

Each unique actual assault in discernment layer is the slide attack that is essentially the lack of a particular key. therefore, Biryukov and Wagner proposed severa enhancements in sliding assaults within the assenting plaintext and discern content fabric [17] yet could not help to make sure facts for all low memory tool calculations. in the ones attacks, the assailant basically misuses the shortcomings substantively in the key timetable. on this manner, the principle issues to bear in thoughts is to pick out a fitting a ways flung discernment layer calculation for mHealth that has a awesome deal a good deal less capability assaults and undertaking to improve these attacks to make it extra tested for destiny mHealth.

\section{PROBLEMS IN ENCRYPTION SET OF REGULATIONS IN MHEALTH\& RESULTS}

Due to the fact the restorative statistics has enormous degree of information however the cellular cellular phone has memory impediments, the encryption calculation must be chosen carefully to maintain in thoughts specific parameters like safety and computational issues. on this way, U. Pandey [18] functions 3 noteworthy troubles that must be stored as lots as encode mhealth information. The issues are as a ways as encryption framework wherein it must be computationally comfy, the encryption and unscrambling have to be quicker, and the security instrument ought to be adaptable.

Within the writing, many light-weight rectangular figures with amazing plan strategies were tested within the direction of the maximum modern-day couple of years. furthermore, NIST prescribed the mild-weight calculations which can also deliver same diploma of protection contrasted with AES that have to be implemented for those restricted memory compelled gadgets for cryptography motive [19]. therefore, a close to exam amongst numerous types of light-weight calculations which can be suitable for low reminiscence gadgets is delineated in table 1 .

Table 1. Lightweight Symmetric Algorithm

\begin{tabular}{|c|c|c|c|c|c|c|c|}
\hline \multirow{2}{*}{$\begin{array}{l}\text { Algorith } \\
\text { m Name }\end{array}$} & \multicolumn{4}{|c|}{ Algorithm Parameters } & \multirow{2}{*}{$\begin{array}{l}\text { Complexity of } \\
\text { Algorithm }\end{array}$} & \multirow{2}{*}{ Merits } & \multirow{2}{*}{$\begin{array}{l}\text { Performance against } \\
\text { Attacks /Security }\end{array}$} \\
\hline & $\begin{array}{l}\text { Key } \\
\text { Size }\end{array}$ & Rounds & $\begin{array}{l}\text { FOM } \\
\text { Value }\end{array}$ & Rotation & & & \\
\hline $\mathrm{AES}$ & $\begin{array}{l}128,192, \\
256 \text { bits. }\end{array}$ & $\begin{array}{l}10,12, \\
14\end{array}$ & 15.3 & $2 \mathrm{D}, 3 \mathrm{D}$ & $\begin{array}{l}\text { Large memory } \\
\text { needs to store S- } \\
\text { box. }\end{array}$ & Faster speed. & $\begin{array}{l}\text { A chosen plaintest can } \\
\text { break } 128 \text { bits AES up to } \\
\text { seven, eight rounds of } \\
192 \text { and } 256 \mathrm{AES}[20] \\
\text { Related key attacks. }\end{array}$ \\
\hline $\begin{array}{l}\text { PRESEN } \\
\mathrm{T}\end{array}$ & $\begin{array}{l}80 \text { or } 120 \\
\text { bits [47]. }\end{array}$ & 32 & 11.3 & $2 \mathrm{D}$ & $\begin{array}{l}\text { The S box of } \\
\text { PRESENT is } \\
\text { weak that } \\
\text { consumes large } \\
\text { cycles in software } \\
\text { level [21]. }\end{array}$ & $\begin{array}{l}\text { The } \\
\text { PRESENT } \\
\text { algorithm is } \\
\text { energy } \\
\text { efficient with } \\
\text { low gate area. }\end{array}$ & Side channel attacks. \\
\hline HIGHT & 128 bits. & 32 & 14.1 & $2 \mathrm{D}$ & $\begin{array}{l}\text { Rounder needs to } \\
\text { enhance security. }\end{array}$ & $\begin{array}{l}\text { Ultra- } \\
\text { lightweight. }\end{array}$ & $\begin{array}{l}\text { Biclique attacks and } \\
\text { impos sible differential } \\
\text { attack on } 26 \text { rounds [22]. }\end{array}$ \\
\hline CLEFIA & $\begin{array}{l}128,192 \\
\text { and } 256 \\
\text { bits. }\end{array}$ & 18 & 9.5 & $2 \mathrm{D}$ & $\begin{array}{l}\text { Only suitable for } \\
\text { small size } \\
\text { plaintext [23]. }\end{array}$ & $\begin{array}{l}\text { Good } \\
\text { performance } \\
\text { and secured } \\
\text { with efficient } \\
\text { energy. }\end{array}$ & $\begin{array}{l}\text { Saturation and Key } \\
\text { recovery attack. }\end{array}$ \\
\hline $\begin{array}{l}\text { CAMEL } \\
\text { LIA }\end{array}$ & $\begin{array}{l}128,192 \\
\text { and } 256 .\end{array}$ & $24 / 18$ & 10 & $2 \mathrm{D}$ & $\begin{array}{l}\text { Computational } \\
\text { complexity [24]. }\end{array}$ & $\begin{array}{l}\text { Better in brute } \\
\text { force attack on } \\
\text { keys. }\end{array}$ & $\begin{array}{l}\text { Impos sible Differential } \\
\text { attack. }\end{array}$ \\
\hline TWINE & 64 bits. & 36 & 13.5 & $2 \mathrm{D}$ & $\begin{array}{l}\text { High FOM to } \\
\text { implement in } \\
\text { hardware. }\end{array}$ & $\begin{array}{l}\text { Software } \\
\text { performance is } \\
\text { good for faster } \\
\text { operation [25]. }\end{array}$ & $\begin{array}{l}\text { Saturation attack Meet in } \\
\text { middle attack. }\end{array}$ \\
\hline
\end{tabular}


ISSUES IN LIGHTWEIGHT ENCRYPTION ALGORITHM FOR MHEALTH

\begin{tabular}{|l|l|l|l|l|l|l|l|}
\hline SPECK & 128 bits. & 32 & 5 & 2D & $\begin{array}{l}\text { Rounder needs to } \\
\text { enhance security. }\end{array}$ & Low gate area. & $\begin{array}{l}\text { Boomerang andKey } \\
\text { Recovery attack [26]. }\end{array}$ \\
\hline SIMON & 128 bits. & 64 & 6.9 & 2D & $\begin{array}{l}\text { Mathematical } \\
\text { operation is quite } \\
\text { high [26]. }\end{array}$ & $\begin{array}{l}\text { Almost free } \\
\text { from attacks. } \\
\text { With low } \\
\text { FOM. }\end{array}$ & Differential Attacks. \\
\hline $\begin{array}{l}\text { RECTA } \\
\text { NGLE }\end{array}$ & 128 bits. & 25 & 7.8 & 2D & $\begin{array}{l}\text { Need more } \\
\text { rounds to enhance } \\
\text { security. }\end{array}$ & $\begin{array}{l}\text { Resistive for } \\
\text { differential, } \\
\text { linear and key } \\
\text { schedule } \\
\text { attacks [27]. }\end{array}$ & $\begin{array}{l}\text { Related key slide and } \\
\text { statistical saturation } \\
\text { attack. }\end{array}$ \\
\hline SPARX & 128 bits. & 24 & 12.9 & 2D & High FOM. & $\begin{array}{l}\text { Almost free } \\
\text { from side } \\
\text { channel attack. }\end{array}$ & Integral attacks [28]. \\
\hline
\end{tabular}

\section{DISCOURSE ON MHEALTH ENCRYPTION SET OF POLICIES TROUBLES}

The encryption calculations are utilized for undertaking protection and privacy throughout statistics sharing. As open key cryptography isn't always considered in late studies due to its highly-priced key calculation, longer keys, animal power assault, convoluted key movement and useful resource, on this way it winds up required to devise light-weight protection solutions for facts transmission in mHealth. The conventional cryptography arrangements center in giving bizarre portions of protection but supply no interest to the obliged devices requirements. Alongside the ones strains, light-weight cryptography (LWC) is an exploration location that has created lately and centers in planning plans for devices with pressured capacities in electricity deliver, availability, tool and programming. For this attitude, S. T. Patel and N. H. Mistry gift numerous forms of lightweight cryptography calculations which can be beneficial to use in cellular telephones for its restricted handling power, limited functionality, low statistics switch ability and coffee power [29]. Similarly, M. Usman proposed a lightweight encryption calculation named as sit wherein it makes use of symmetric key calculation for encryption manner which contains of some encryption rounds [30]. Every encryption spherical is predicated upon on some numerical capacities to make perplexity and dispersion. For this reason, the mild-weight parent offers splendid security like unique figures for a more noteworthy variety of rounds but ultimately builds using obliged power which likewise corrupts the presentation of the parent.

By means of way of the with the aid of, a few problems are as however a key subject point for mHealth utilization that includes the set amount of encryption calculations that's low-cost for mHealth to make the trade off amongst cost, execution, for instance, light-weight, much less reminiscence, quicker tempo and comfy which may be very difficult to plan together. Moreover, the past calculations that are ordinary for mHealth utilize a more outstanding variety of rounds to decorate the security of information. Consequently the more adjusts corrupt the determine execution just as make the activity more slow. The low FOM is likewise required for mHealth calculations to effects execute in system [5]. On this manner, a exquisite scrambled calculation that have to be satisfy the above stipulations, is anticipated to plot for mHealth to guarantee appropriate safety on affected person's information which moves from versatile to discernment layer earlier than transmitting the cellular or high-quality structures. In this way, the hugeness of the exam is to propose a stable light-weight encryption calculation a number of the modern calculations looking at their blessings and faults that allows you to deliver a secure facts transmission in a ways off discernment layer with the aid of the usage of scrambling the vital indicators of a affected character's facts simply as low computational charge and faster pace requirements.

The proposed calculation need to provide a primary shape absolutely as less expensive for usage in mHealth circumstance. Some incredible light-weight square figures which have been referred to in past phase like AES, present, CAMELLIA, Tripe DES, CLEFIA and SIMON deliver higher execution however furthermore confronting some attacks which an notable test are to guarantee valid safety in mHealth condition. Henceforth the later calculations are supposed for statement layer protection with beating a big variety of the safety treats of the beyond referenced calculations yet on the equal time they're now not placing to be applied in mHealth. In this way, the proposed calculations of mHealth might be considered as RECTANGLE, SIMON and SPARX which want to structure in a propelled degree to evacuate every one of the awful marks contrasted with contemporary one.

For RECTANGLE, it opposes direct and differential attacks for least 25 rounds square determine yet under 25 rounds like 18 or 14 round duration square determine can not provide legitimate safety from the referenced assaults. Further, RECTANGLE faces slide assault, associated key attack and measurable immersion assault which want to improve in future with diminishing extensive variety of rounds for higher execution in mHealth. Further, one of the promising focal elements of SIMON is the FOM esteem that is 6.Nine, taken into consideration as the $1 /$ three least FOM esteem among all of the satisfactory light-weight figures. Consequently, SIMON execution is good for its littler FOM but its scientific interest is excessive and faces differential attack which wants to improve in destiny plan. Furthermore, the SPARX calculation FOM is immoderate ( 8.6 for sixty four rectangular size and 12.9 for 128 square length), that is resistive in the direction of differential and directly 
cryptanalysis super. Alongside those lines, SPARX is the continued improvement so as to be smarter to apply in
mHealth but want to lower FOM for easy system execution

Table 2. Comparison of Algonthm in Perception Layer

\begin{tabular}{|l|l|}
\hline Algorithm Name & \multicolumn{1}{|c|}{ Future Solutions to use in mHealth } \\
\hline RECTANGLE & $\begin{array}{l}\text { It takes minimum 25 rounds to give proper security that degrades the cipher performance which is not } \\
\text { acceptable for mobile. Thus, an advanced RECTANGLE needs to be designed that has a smaller } \\
\text { number of rounds with improving slide attack, relatedkey attack and statistical saturation attack. }\end{array}$ \\
\hline SIMON & This algorithm should be modified in an advancedlevel to minimize differential attackproperly. \\
\hline SPARX & $\begin{array}{l}\text { The FOM is too HIGH. The future design should be focused on reduced FOM for simple } \\
\text { implementationinhardware. }\end{array}$ \\
\hline
\end{tabular}

\section{GIVE UP}

On this paper, considered one of a kind slight-weight calculations are tested truly with the resource of the usage of tending to the issues of lightweight encryption calculation and protection in mHealth. From talk, correlation amongst light-weight calculation demonstrates that RECTANGLE might be given higher execution contrasted with FOM and in term of protection perspectives. in addition, the second RECTANGLE safety is upgraded utilising increasingly more type of rounds, this makes a noteworthy hassle to execute in mHealth. in this way, a propelled 3-D RECTANGLE may be proposed to deal with the above requirements that supply better execution calculation for its turn contrasted with 2 nd RECTANGLE. consequently, the quantity of rounds might be dwindled for the proposed calculation with ensuring extra protection for making revolution of every estimation of plaintext which gives showed mHealth calculation in a while.

\section{CONFIRMATION}

The creators might probable need to provide their manner to Universiti Sains Islam Malaysia (USIM) for the help and places of work gave.

\section{REFERENCES}

1. F. Zubaydi, A. Saleh, F. Aloul. (2015). safety of portable health (mhealth) frameworks. IEEE 15th worldwide collecting on bioinformatics and bioengineering (BIBE). Pp. 1-5.

2. A. Kumar, Suman, Renu. (2008). Correlation of $3 \mathrm{G}$ faraway structures and $4 \mathrm{G}$ a long way off systems. worldwide magazine of Electronics and conversation Engineering. quantity 6. Pp. 1-8.

3 P. okay. Kushwaha. (2014). A have a study on mild-weight rectangular figures. ordinary magazine of laptop software. amount 96.

4. I. Bhardwaj, A. Kumar, M. Bansal. (2017). An audit on moderate-weight cryptography calculations for records safety and affirmation in iots. gathering on signal Processing, Computing and control, IEEE.

5. D. Dinu, A. Biryukov, J. Grobschadl, D. Khovratovich, Y. L. Corre, Léo and Perrin. (2015). FELICS-inexpensive assessment of slight-weight cryptographic frameworks. NIST workshop on light-weight Cryptography, countrywide Institute of necessities and era (NIST).

6. J X. Lin, R. Lu, X. Shen. (2009). A robust safety saving plan in the direction of global listening stealthily for eHealth frameworks. IEEE J. Sel. Territories communique. quantity 27. Pp. 365-377.

7. L. Guo, C. Zhang, J. solar. (2014). A protection saving amazing based totally validation framework for bendy wellbeing structures. IEEE Trans. transportable pc. amount 13. Pp. 1927-1941.

8. D. Weerasinghe, M. Rajarajan, V. Rakocevic. (2009). protection insurance on take into account assigned records in open transportable structures. familiar conference of electronic Healthcare.

9. R. Adhikari, D. Richards. (2014, Dec). protection and safety troubles recognized with the usage of portable health programs. 25 th Australian convention on statistics system.
10. D. Kotz, C. A. Gunter, S. Kumar, J. P. Weiner. (2016, June). protection and protection in bendy well-being: an exploration plan. The IEEE computer Society. amount forty 9 (6).

11. L. R. Knudsen. Cryptanalysis of LOKI91 propels in cryptology. techniques of Springer-Verlag. Pp. 196-208.

12. E. Biham, A. Shamir. (1990). Differential cryptanalysis of des-like cryptosystems. A. Menezes and S. A. Vanstone, editors, CRYPTO extent 537. Pp. 2-21.

13. L. R. Knudsen. (1994). Truncated and better request differentials. B. Preneel, manager, FSE. amount 1008. Pp. 196-211.

14. E. Biham, A. Biryukov, A. Shamir. (1999). Cryptanalysis of skipjack faded to 31 rounds utilizing incomprehensible differentials. J. Stern, proofreader, EUROCRYPT. quantity 1592. Pp. 12-23.

15. D. Wagner. (1999). The boomerang assault. FSE. quantity 1636 . Pp. 156-one hundred and seventy.

16. H. M. Heys. an instructional exercise on direct and differential cryptanalysis.

17. A. Biryukov, D. Wagner. (1999). Slide attacks. Pre methods of rapid software application Encryption Workshop.

18. U. Pandey, M. Manoria, J. Jain. a completely unique approach for picture encryption through new $m$ region encryption calculation using rectangular based completely change alongside blend interest. international mag of laptop programs. volume 40 . Pp. 0975 - 8887.

19. Computerworld mag (2011). AES display powerless by using manner of Microsoft professionals.

20. A. Moradi, A. Poschmann. (2017). a very conservative and an element execution of AES. Advances in Cryptology. amount 6632. Pp. 69-88.

21. A. Bogdanov. (2007). gift: a distinctly-light-weight square discern cryptographic device and implanted frameworks. CHES. speak Notes in laptop era.

22. D. Hong. (2006). every other square determine low-value for low-asset gadget. Cryptographic hardware and Embedded systems.

23. T. Akishita, H. Hiwatari. (2012). quite conservative tool utilization of the rectangular determine CLEFIA. Cryptography Lecture Notes in computer technology Springer. Pp. 278-292.

24. A. Satoh, S. Morioka. (2003). gadget focused execution exam for the standard square figures AES, camellia, and triple-des. software program program engineering facts protection, Springer. Pp. 252-266.

25. P. ok. Kushwaha. (2015). A evaluation on light-weight square figures. famous magazine of laptop applications. amount 96. Pp. 1-7.

26. R. Beaulieu, D. Shors. (2015). The simon and be aware mild-weight rectangular figures. approaches of the 52nd Annual layout Automation conference.

27. W. Zhang, Z. Bao. (2015). rectangular shape: a bit-cut light-weight square parent suitable for numerous levels. China records Sciences amount fifty eight. Pp 1-15.

28. D. Dinu, L. Perrin. (2017). SPARX: a group of arx-based absolutely light-weight rectangular figures provably comfortable in the direction of right away and differential assaults. strategies of Asiacrypt 16 .

29. S. T. Patel, N. H. Mistry. (2015). A assessment: light-weight cryptography in WSN. general convention on conversation Networks (ICCN). IEEE

30. M. Usman, I. Ahmed. (2017). sit down: a slight-weight encryption calculation for at ease net of things. not unusual mag of superior computer generation and packages. quantity 8 (1). 


\section{AUTHORS PROFILE}

Tasnuva Ali received her MSc degree in Telecommunication Engineering from North South University, Bangladesh. She also obtained her BSc degree in Electronics and Telecommunication Engineering from Daffodil International University, Bangladesh. She is pursuing her $\mathrm{PhD}$ degree at the Faculty of Science and Technology, Universiti Sains Islam Malaysia (USIM). Now she is working as an Assistant Professor in Electronics and Telecommunication Engineering department at Daffodil International University. Her research interests include cryptography, data security and wireless sensor network.

Dr. Azni Haslizan obtained her bachelor's degree in Computer Information Systems from Bradley University, Illinois, USA in 1998 and M.Sc in Digital Communication from Monash University, Clayton Australia in 2002. She received her $\mathrm{PhD}$ in Computer Science (Wireless Security) from Universiti Technical Melaka Malaysia (UTeM) in 2014. From May 2003 until May 2007, she was at the Faculty of Computer Science and Information Technology, Universiti Malaysia Sarawak (UNIMAS). She joins Universiti Sains Islam Malaysia (USIM) in May 2007 and has been appointed as Deputy Dean of Centre for Graduate Studies. She has many experiences in presenting research talks and papers at national and international conferences. She has also published tremendous articles in highly esteemed journals. Her research interests are on Wireless Security, IoTs, and Cryptography. 